\title{
Article
}

\section{Do people who consciously attend to their movements have more self-reported knee pain? An exploratory cross-sectional study}

Selfe, James, Dey, Maria Paola, Richards, Jim, Cook, Neil, Chohan, Ambreen, Payne, Katherine and Masters, $R$

Available at http://clok.uclan.ac.uk/10799/

Selfe, James, Dey, Maria Paola, Richards, Jim ORCID: 0000-0002-4004-3115, Cook, Neil ORCID: 0000-0001-9738-9582, Chohan, Ambreen ORCID: 00000003-0544-7832, Payne, Katherine and Masters, $R$ (2014) Do people who consciously attend to their movements have more self-reported knee pain? An exploratory cross-sectional study. Clinical Rehabilitation, 29 (1). pp. 95-100. ISSN 0269-2155

It is advisable to refer to the publisher's version if you intend to cite from the work. http://dx.doi.org/10.1177/0269215514536208

For more information about UCLan's research in this area go to http://www.uclan.ac.uk/researchgroups/ and search for <name of research Group>.

For information about Research generally at UCLan please go to http://www.uclan.ac.uk/research/

All outputs in CLoK are protected by Intellectual Property Rights law, including Copyright law. Copyright, IPR and Moral Rights for the works on this site are retained by the individual authors and/or other copyright owners. Terms and conditions for use of this material are defined in the policies page. 


\section{Introduction}

Fear-related anticipation of pain can cause altered muscular activation and guarded movements ${ }^{1,2}$ and is associated with hyper-vigilance to cues that indicate pain, or the corollaries of pain. The ability to shift attention away from pain-related stimuli is also impaired. ${ }^{3}$ Psychological and biomechanical mechanisms that underlie movement-related pain responses are often considered in isolation, but conscious aspects of movement may influence the manner in which they combine to contribute to musculoskeletal pain responses. ${ }^{4}$

The theory of reinvestment proposes that individual differences in the propensity that people have for conscious involvement in their movements plays a role in the way they respond to various factors known to influence movement control. ${ }^{4,5}$ The Movement Specific Reinvestment Scale, a reliable scale with construct validity, was developed specifically to measure the propensity for conscious involvement in movement. ${ }^{6}$ The scale consists of two five-item subscales. The Conscious Motor Processing subscale reflects a person's tendency to consciously control their movements whereas the Movement Self-Consciousness subscale reflects a person's concerns about their style of movement and about making a good impression when they move. Responses to the Movement Specific Reinvestment Scale are recorded using a Likert-type scale with each item ranging from one (strongly disagree) to six (strongly agree).

Normative values in younger general populations have not been reported previously, but higher scores on the Movement Specific Reinvestment Scale have been shown to be associated with greater movement disruption under psychological pressure in sports 
performers ${ }^{6}$ higher fall incidence in elderly people,${ }^{7}$ and more severe functional impairment following stroke. ${ }^{8}$ It has been concluded from these studies that people with a high propensity for movement specific reinvestment are more likely to consciously monitor and control their movements, which can disrupt more effective automatic-control processes. ${ }^{5}$

To date efforts to understand the causes of knee pain, especially patellofemoral pain, mostly focus on the biomechanical factors that contribute to the pain rather than psychological factors or the interaction between biomechanical and psychological factors. In this regard, it is surprising that the role of movement specific reinvestment in musculoskeletal knee pain has not been investigated previously given that conscious attention is mobilized by factors such as fear or anxiety ${ }^{5}$ and that people may attempt to modify the mechanics of their movement in order to adapt to pain or anticipated pain. ${ }^{4}$ Investigation of the role of movement specific reinvestment in knee pain is therefore potentially useful considering the importance of the knee in human locomotion. This study explored the relationship between Movement Specific Reinvestment Scale scores and self-reported knee pain in a group of young and middle-aged adults. A higher general propensity for movement specific reinvestment was expected to be associated with a greater likelihood of self-reported knee pain, either because the tendency to be consciously involved in movement causes knee problems that lead to pain or because knee pain causes a person to become more consciously engaged in their movements. 


\section{Methods}

This exploratory study used questionnaire data initially collected to describe movement specific reinvestment and the prevalence of knee pain in young and middle-aged adults. The participants were a convenience sample of adults aged 18 to 55 attending a three day university science fair in 2012; participants included staff, students and the general public. Those unable to complete the questionnaire were excluded. Participants, who consented to be involved, self-completed the Movement Specific Reinvestment Scale as well as questions about knee pain and clinical characteristics of self-reported knee pain (presence of swelling, duration of pain, laterality, sudden or gradual onset). ${ }^{9}$ The question about knee pain 'have you had pain or problems in the last year in or around the knee?' was modified from the knee pain screening tool, validated for use in large scale population-based studies. ${ }^{10}$ Body mass index, estimated from directly measured weight and height, was categorised as not overweight (body mass index <25) and overweight (body mass index, 25 and over). University ethical committee approval was obtained.

This data has been used to explore the association between the Movement Specific Reinvestment Scale subscale scores (Conscious Motor Processing and Movement Selfconsciousness) and self-reported presence of musculoskeletal knee pain. Differences in mean scores between those with and without knee pain and between different demographic and body mass index groups were investigated using unpaired t-tests. Binary logistic regression was used to explore the association between self-reported knee pain and Movement Specific Reinvestment subscale scores, controlling for age, gender and body mass index. For each clinical characteristic (whether the knee ever swells up, whether the knee pain had lasted more than one month, whether the knee pain was bilateral and whether the onset of the knee 
pain followed sudden injury), differences in mean scores were compared across those without knee pain, those with knee pain with the clinical characteristic, and those with knee pain without the clinical characteristic, using one-way analysis of variance and, if statistically significant, between each two-way comparison, for example, those with the clinical characteristic and those without knee pain, using unpaired t-tests.

\section{Results}

Of the 101 participants, 34 (33.7\%) responded positively to the question 'have you had pain or problems in the last year in or around the knee?' and were classified as having selfreported knee pain (Table 1). Scores on the Movement Specific Reinvestment Scale were available for 99 participants. Mean Conscious Motor Processing subscale scores, but not mean Movement Self-consciousness subscale scores, were significantly higher in those with knee pain compared to those without knee pain (mean difference 3.03 ; t-test $2.66, \mathrm{df}=97$, $\mathrm{P}=0.009 ; 95 \%$ CI 0.77 to 5.30; Table 1). Conscious Motor Processing subscale score was an independent predictor of knee pain when controlling for Movement Self-consciousness subscale score, age, gender and body mass index, with the odds of knee pain increasing by $16 \%$ for each point increase in the subscale score $(n=96$, adjusted odds ratio $1.16 ; 95 \%$ CI 1.04 to 1.30$)$.

For all of the clinical characteristics investigated, statistical differences were evident between groups for Conscious Motor Processing scores but not for Movement Self-conscious scores(Table 2). With the exception of one clinical characteristic, (sudden or gradual onset of knee pain), those who reported knee pain with the characteristic and those who reported knee 
pain without the characteristic had statistically significantly higher mean scores than those without knee pain. However, for sudden or gradual onset of knee pain, only those who reported that their knee pain came on following a sudden injury demonstrated a significantly higher mean score compared to those without knee pain (difference in mean score 5.9; $\mathrm{t}=3.30, \mathrm{df}=75, \mathrm{P}=0.01 ; 95 \% \mathrm{CI} 2.36$ to 9.53$)$. There was no significant difference between those with knee pain which was not of sudden onset and those without knee pain $(\mathrm{P}=0.21)$.

\section{Discussion}

Overall, a propensity for movement specific reinvestment appeared to be associated with selfreported knee pain in the participants, with conscious motor processing, rather than movement self-consciousness. Previous studies have also found that propensity for conscious motor processing plays a more prominent role than movement self-consciousness in people with movement related problems, such as falling, ${ }^{7}$ stroke, ${ }^{8}$ and Parkinson's disease. ${ }^{11}$ These findings suggest that concerns about moving effectively (or safely), which are likely to involve conscious motor processing, outweigh concerns about making a good impression when moving, which are likely to involve movement self-consciousness.

Compared to people without knee pain and people who reported gradual onset of knee pain, conscious motor processing scores were significantly higher in those who reported knee pain due to sudden injury. The Movement Specific Reinvestment Scale is a trait scale so it is plausible that those more likely to consciously process their movements are prone to knee injury perhaps because they may be more guarded when they move. ${ }^{2}$ The lack of an association with gradual onset of knee pain militates against pain catastrophising by those with high conscious motor processing scores, but we acknowledge that this was a cross- 
sectional design, which precludes establishing the direction of the relationship. It is equally plausible that, consistent with fear-avoidance models, knee pain leads to increased conscious motor processing.

Previous studies of movement specific reinvestment suggest that a five to eight unit difference in scores on the Scale is clinically relevant. ${ }^{7,8,11}$ In this study, a mean difference in Conscious Motor Processing subscale scores of only 3.3 units was observed between those with or without knee pain; however, this would increase the likelihood of knee pain by approximately $50 \%$. Moreover, the difference in mean scores between those without knee pain and those with knee pain due to sudden injury was nearly 6 units, notwithstanding that the sample size was small and the confidence intervals consistent with a much smaller increase.

Participants in the study were a convenience sample rather than a random population sample, but knee pain rates and their gender distribution were similar to population-based studies, ${ }^{12,13}$ which suggests that the findings may be generalizable. This study is a post hoc analysis of a database containing information on the Movement Specific Reinvestment Scale and selfreported knee pain. Because of the opportunistic nature of the study a limited number of factors were available for inclusion in the analysis and no formal sample size estimation was possible, so the exploratory approach to the regression analysis may have caused the data to be over-fitted, giving rise to an optimistic interpretation of the findings. 
Nevertheless the potential implications of the findings are wide-ranging. There are possible public health implications because of the potential for negative health consequences associated with activity avoidance. ${ }^{3}$ There is increasing international interest in stratifying patients with musculoskeletal problems based on clinical and psychological characteristics in order to optimise individual patient management. ${ }^{14}$ For example potential clinical sub-groups in patellofemoral pain are currently being investigated ${ }^{15}$; and in back pain there is interest in targeting interventions to sub-groups using psychosocial characteristics. ${ }^{16}$ The propensity for movement specific reinvestment may play a role in individual responsivity to pain or to the mechanisms that underlie causes of pain, which could be an important consideration for targeted rehabilitation strategies in different individuals. Knee pain patients with a high propensity for movement specific reinvestment may need different rehabilitation strategies compared to those with a low propensity. Equally, elite sports performers with a high propensity for movement specific reinvestment may require targeted preventative interventions because they are more prone to knee injury. In such cases, implicit rehabilitation strategies that target unconscious aspects of movement may be preferred over explicit strategies that target conscious aspects. ${ }^{17,18}$, Further research to substantiate the preliminary findings of this study is warranted using large-scale prospective designs in general and sporting populations.

\section{Clinical Message}

- knee pain is more commonly reported by people with a propensity for conscious involvement in their movements 
- The propensity for conscious involvement in movement may play a role in individual responsivity to knee pain or to the mechanisms that underlie knee pain and hence may be useful in directing rehabilitation strategies.

\section{Acknowledgements}

The last author was supported by a Distinguished Scholar award from the University of Central Lancashire. We would like to thank Renuka Erande and Dr Jessie Janssen for assistance in data collection.

\section{Conflict of Interest Statement}

The authors declare that they have no competing interests.

\section{Contributors}

JS, RM and PD conceived and designed the study; AC and KP collected and collated the data; JS, RM, PD and JR developed the analytical plan and interpreted the data findings; PD and NC undertook analysis of the data; JS, RM, JR and PD wrote the paper; all authors commented on drafts and have seen the final draft. JS is guarantor of the study.

\section{References}


1. Moseley GL, Hodges PW. Reduced variability of postural strategy prevents normalization of motor changes induced by back pain: A risk factor for chronic trouble? Behav Neurosci. 2006;120:474-6.

2. Main CJ, Watson PJ. Guarded movements: development of chronicity. J Musculoskelet Pain. 1996;4:163-70.

3. Leeuw M, Goosens ME, Linton SJ, Crombez G, Boersma K, Vlaeyen JW. The fearavoidance model of musculoskeletal pain: current state of scientific evidence. J Behav Med. 2007;30:77-94

4. Lethem J, Slade P, Troup J, Bentley G. Outline of fear-avoidance model of exaggerated pain perception. Behav Res Ther. 1983;21:401-8.

5. Masters RSW, Maxwell J. The theory of reinvestment. Int Rev Sport Exerc Psychol. 2008;1:160-83.

6. Masters RSW, Eves FF, Maxwell J. Development of a movement specific reinvestment scale. In Morris T, Terry P, Gordon S, Hanrahan S, Ievleva L, Kolt G, Tremayne P, editors. Proceedings of the ISSP 11th World Congress of Sport Psychology, Sydney, Australia. 2005.

7. Wong WL, Masters RS, Maxwell JP, Abernethy AB. Reinvestment and falls in community-dwelling older adults. Neurorehabil Neural Repair. 2008;22:410-4.

8. Orrell AJ, Masters RS, Eves FF. Reinvestment and movement disruption following stroke. Neurorehabil Neural Repair 2009;23:177-83.

9. Callaghan M, Selfe J, Dey P. Activity associated pain in patellofemoral pain syndrome: how does it inform research and practice? Physiotherapy. 2009;95:321-322.

10. Jinks C, Lewis M, Ong BN, Croft P. A brief screening tool for knee pain in primary care. 1. Validity and reliability. Rheumatology (Oxford). 2001;40:528-36. 
11. Masters RS, Pall HS, MacMahon KMA, Eves FF. Duration of Parkinson disease is associated with an increased propensity for 'reinvestment'. Neurorehabil Neural Repair. 2007;21:123-6.

12. Zhai G, Cicuttini F, Ding C, Scott F, Garnero P, Jones G. Correlates of knee pain in younger subjects. Clin Rheumatol. 2007;26:75-80.

13. Boling M, Padua D, Marshall S, Guskiewicz K, Pyne S, Beutler A. Gender differences in the incidence and prevalence of patellofemoral pain syndrome. Scand J Med Sci Sports. 2010;20:725-30.

14. Foster NE, Dziedzic KS, van der Windt DAWM, Fritz JM, Hay EM: Research priorities for non-pharmacological therapies for common musculoskeletal problems: nationally and internationally agreed recommendations. BMC Musculoskeletal Disorders 2009, 10: 3 .

15. Selfe J, Callaghan M, Witvrouw E, Richards J, Dey MP, Sutton CJ, Dixon J, Martin D, Stokes M, Janssen J, Ritchie E, Turner D (2013) Study Protocol: Targeted Interventions for Patellofemoral Pain (TIPPs): classification of clinical sub-groups. BMJ Open. . 3:e003795 doi:10.1136/bmjopen-2013-003795

16. Hill JC, Dunn KM, Lewis M, Mullis R, Main CJ, Foster NE, Hay EM. A primary care back pain screening tool: identifying patient subgroups for initial treatment. Arthritis Rheum. 2008 May 15;59(5):632-41. doi: 10.1002/art.23563.

17. Masters, RSW. Knowledge, knerves and know-how: The role of explicit versus implicit knowledge in the breakdown of a complex motor skill under pressure. Br J Psychol. 1992;83:343-58.

18. Orrell AJ, Eves FF, Masters RSW. Motor learning of a dynamic balancing task after stroke: Implicit implications for stroke rehabilitation. Phys Ther. 2006;86:369-80. 
Table 1: Distribution of study population characteristics and mean reinvestment scores in subgroups of the study population (N=101)

\begin{tabular}{|c|c|c|c|c|c|}
\hline Characteristic & $\mathrm{n}(\%)$ & $\begin{array}{l}\text { Knee pain } \\
\text { prevalence } \\
\mathrm{n}(\%)\end{array}$ & $\begin{array}{l}\text { Movement Specific } \\
\text { Reinvestment } \\
\text { Mean total score (SD) }\end{array}$ & $\begin{array}{l}\text { Movement Self- } \\
\text { consciousness } \\
\text { Mean score (SD) }\end{array}$ & $\begin{array}{l}\text { Conscious Motor } \\
\text { Processing } \\
\text { Mean score (SD) }\end{array}$ \\
\hline Knee Pain & & & & & \\
\hline $\begin{array}{l}\text { Presence } \\
\text { Absence }\end{array}$ & $\begin{array}{l}34(33.7 \%) \\
67(66.3 \%)\end{array}$ & & $\begin{array}{l}34.2(10.17) \\
30.8(10.15) \\
2 \text { missing }\end{array}$ & $\begin{array}{l}14.8(6.83) \\
14.3(5.92) \\
2 \text { missing }\end{array}$ & $\begin{array}{l}19.5(5.34)^{*} \\
16.4(5.34) \\
2 \text { missing }\end{array}$ \\
\hline $\begin{array}{l}\text { Age in years } \\
<25 \\
25-34 \\
35-55\end{array}$ & $\begin{array}{l}\text { Mean } 30(\text { SD 10.00) } \\
44(43.6 \%) \\
31(30.7 \%) \\
26(25.7 \%)\end{array}$ & $\begin{array}{l}11(25.0 \%) \\
11(35.5 \%) \\
12(46.2 \%)\end{array}$ & $\begin{array}{l}\mathrm{R}=-0.131 \\
34.0(10.07) \\
29.9(11.51) \\
30.8(8.52) \\
2 \text { missing }\end{array}$ & $\begin{array}{l}\mathrm{R}=-0.233 \# \\
16.3(5.65)^{* *} \\
13.7(6.99) \\
12.4(5.48)^{* *} \\
2 \text { missing }\end{array}$ & $\begin{array}{l}\mathrm{R}=0.019 \\
17.7(5.55) \\
16.2(5.83) \\
18.4(5.02) \\
2 \text { missing }\end{array}$ \\
\hline $\begin{array}{l}\text { Gender } \\
\text { Male } \\
\text { Female }\end{array}$ & $\begin{array}{l}43(43.0 \%) \\
57(57.0 \%) \\
1 \text { missing }\end{array}$ & $\begin{array}{l}12(27.9 \%) \\
22(38.6 \%) \\
1 \text { missing }\end{array}$ & $\begin{array}{l}32.5(9.89) \\
31.7(10.58) \\
3 \text { missing }\end{array}$ & $\begin{array}{l}13.9(6.23) \\
15.0(6.26) \\
3 \text { missing }\end{array}$ & $\begin{array}{l}18.6(4.78) \\
16.7(5.86) \\
3 \text { missing }\end{array}$ \\
\hline $\begin{array}{l}\text { Body mass index } \\
<25 \\
=>25\end{array}$ & $\begin{array}{l}\text { Mean } 25.2 \text { (SD 4.20) } \\
54(55.1 \%) \\
44(44.9 \%) \\
3 \text { missing }\end{array}$ & $\begin{array}{l}17(31.5 \%) \\
17(38.6 \%) \\
3 \text { missing }\end{array}$ & $\begin{array}{l}\mathrm{R}=0.111 \\
31.2(8.75) \\
33.0(12.05) \\
4 \text { missing }\end{array}$ & $\begin{array}{l}\mathrm{R}=0.083 \\
14.1(5.29) \\
15.0(7.36) \\
4 \text { missing }\end{array}$ & $\begin{array}{l}\mathrm{R}=0.113 \\
17.1(4.94) \\
18.1(6.21) \\
4 \text { missing }\end{array}$ \\
\hline
\end{tabular}

$\mathrm{R}=$ Spearman's correlation coefficient. \#P $=0.02$

*Mean Conscious Motor Processing score for presence of knee pain compared with absence of knee pain $\mathrm{P}=0.009$; ** mean Movement Selfconsciousness score for $35+$ compared with $<25$ years of age, $\mathrm{P}=0.007$; all other comparisons for presence of knee pain and total and factor reinvestment scores were not statistically significant. 
Table 2: Distribution of reinvestment scores in knee pain subgroups and comparison across those without knee pain, those with knee pain with clinical characteristic and those with knee pain without clinical characteristic $(\mathrm{N}=99)$. F statistics refer to each one-way ANOVA between the three groups.

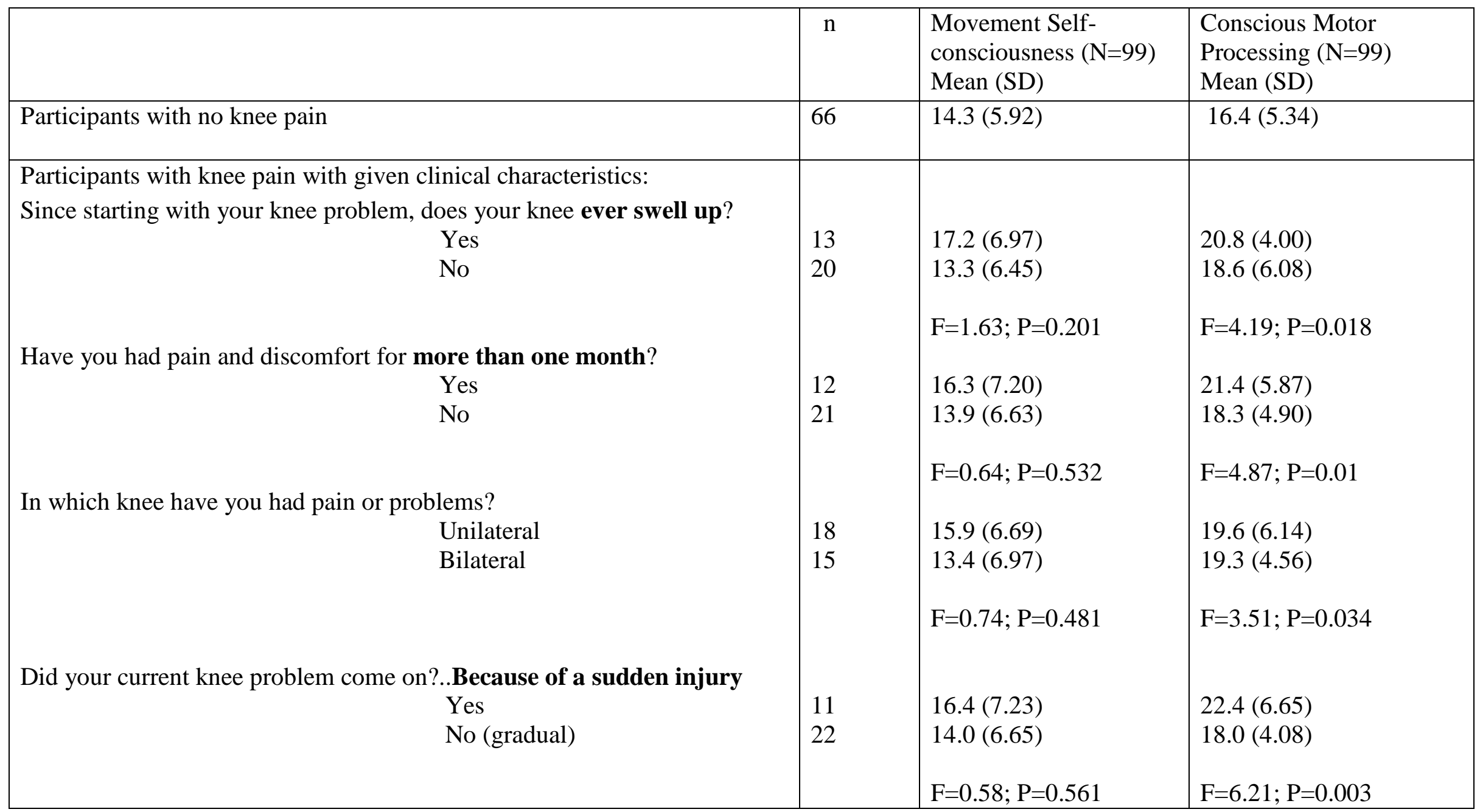

